\title{
Experimental and Numerical method to find solar flux density distribution on a receiver plate from heliostats
}

\author{
Chandradeep Nagarale* and P. M. Gadhe \\ Mechanical Engg. Department, Pune University, MIT Kothrud Pune, India \\ Accepted 15 June 2016, Available online 20 June 2016, Special Issue-5 (June 2016)
}

\begin{abstract}
In a solar central receiver system, solar radiation is concentrated on a tower mounted heat exchanger (receiver) by the use of mirrors called heliostats. To compare the experimental and numerical result for getting the better Flux distribution on the solar central receiver system, a common basis of testing is desirable. This helps in the design and performance prediction of not only receiver, but also a complete system. The method consists of optical test characterization of receiver. This research presents the Focus Test on the receiver and its implementation on solar central receiver system. The test provides the size of the focus, the total solar radiation concentrated, flux distribution and concentration ratio. Result of this test gives the idea about design of receiver and choice of material. The SOLTRACE software, developed by NREL (National Renewable Energy Laboratory, United States) for the numerical work to find out the focus size and flux distribution on the receiver. By using this result with aiming point strategy in SOLTRACE software the even flux distribution and flux image size will be optimized.
\end{abstract}

Keywords: Heliostat, Flux distribution, Area element method.

\section{Introduction}

Solar thermal power often also called Concentrating Solar Power (CSP) is a new technology and it is in nascent stage. For power generation, this technology can use direct solar radiation. Direct solar radiation can be concentrated and collected with the help of solar concentrators to generate heat at medium to high temperatures. This heat is then used to operate a conventional power cycle for example steam turbine or stirling engine. In a solar central receiver, solar radiation is concentrated on a tower-mounted heat exchanger (receiver) by theme of mirrors called heliostats. Heliostats track the sun and reflect the sunlight to the receiver. The complete group of heliostats is called a collector field. The field may surround the tower or the field may be located on one side of the tower. The numerical and experimental work done on Heliostat Technology in India is less. No work is done on the experimental flux measurement of heliostat in India. A tool for analyzing the flux distribution can be of great help to know the optical quality of solar concentrator. Receiver is the heart of solar central receiver system and its play an important role of intercepting reflected solar radiation from the heliostat field and transferring thermal energy to the heat transfer fluid. Here for getting a proper flux on the receiver surface some parameters are tested.

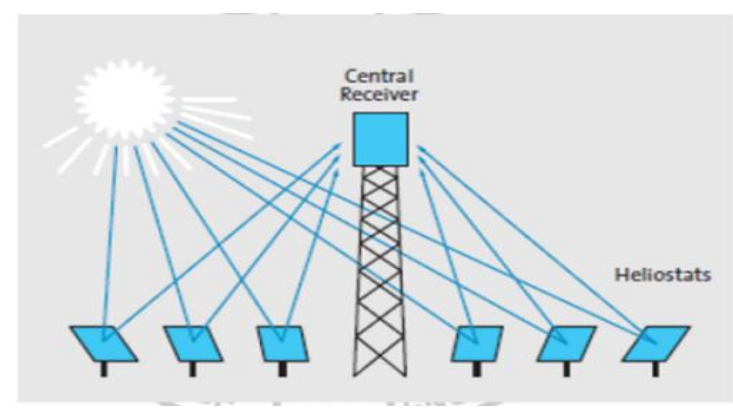

Fig.1. Central receiver system technology

The objective of the research work is to analyze the flux distribution on the receiver plate of the Central Receiver System. For this the thermocouple method is used to determine the concentrated solar flux distribution reflected from heliostat system on the receiver plate. Area element method is used determine the temperature of receiver plate. In this method, each thermocouple is assumed to represent the temperature of a finite area of specific part of receiver. It is assumed that the each thermocouple represents the average temperature of the respective area element. Here ktype thermocouple is used because it has wide range of temperature as compare to other thermocouple and also having a small tolerance.

A lot of research has been done pertaining to this context. V.P. Muley, they have used the method proposed by Rakesh sharma for determining the 
optical performance of a Scheffler dish. In this method the estimation of temperature distribution on the focus plate is carried out more rigorously by measuring temperature at a large number of points on the plate. The test provides the size of the focus, the total solar radiation concentrated, its distribution and concentration ratio. V. Rakesh sharma, focused on the optical quantity of paraboloid concentrator collector, flux distribution and focus size. Glen Johnston, the paper discuss about the focal region measurements of point focus dish concentrator by using charge coupled device to find out the proper flux distribution. Lorin L., The paper discusses about an allowable flux density, optimization techniques for receiver by using aiming strategies and redistributing the heliostat field during design. Alberto Sanchez-Gonzalez[6],this paper represents a methodology to project the flux distribution from the image plane into the panels of any central receiver in solar power tower plants and a methodology was proposed to project the solar flux density from the image plane onto the receiver faces. Clifford Ho [7], the paper discusses the method to obtain flux maps on arbitrary (non-planer) surfaces using a digital photography. Photographic Flux Mapping-PHLUX method was used and results of this method also show that flux distribution can be assumed nearly normally distributed. F. Gohring.[8], the paper suggests indirect flux measuring technique using a CCD camera. This article presented a flux density measurement system developed for open volumetric receivers that can be adapted to other receiver systems. The experiment demonstration shows feasibility of the system and accurate measurement of flux density with fast response time. J. Ballestrin, a direct heat flux measurement system, MDF (Medida Directa de Flujo) system has been designed, mounted and used successful successfully on the top of the SSPS-CRS tower at the Plataforma Solar de Almeria (PSA) to measure the concentrated solar power by heliostat field onto the flat aperture under consideration. In this system, a new type of heat flux sensor, with a $6.32 \mathrm{~mm}$ front face diameter and response time of microseconds, allows extremely fast direct heat flux measurement. Zhirong Liao [10], the paper focus on the allowable flux density. The allowable flux density on a solar central receiver is a significant receiver parameter and is related to the receiver life span and economics. A mathematical model was developed to calculate the allowable flux density for the Solar Two receiver. This model show that a higher allowable flux density can be obtained by increasing the allowable strain of the tube material and the fluid velocity and decreasing the tube thermal resistance.

\section{Experimental Set - up}

The set - up consists of heliostat array and a focus plate. The description of focus plate is given below and the theory of heliostat is explained later.

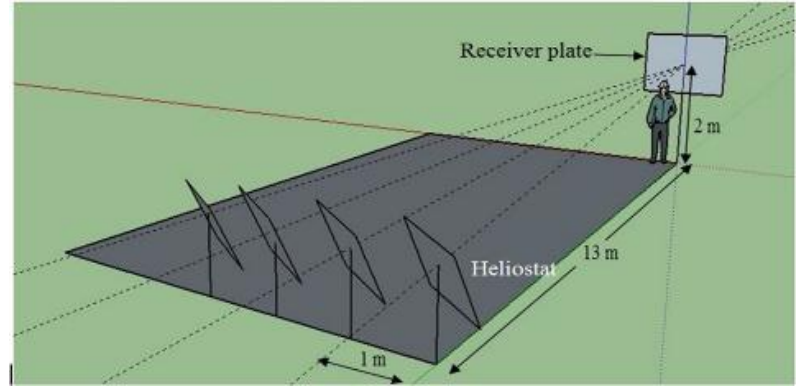

Fig.2. Layout of Heliostat field with receiver

\subsection{Focus plate}

The set-up consists of a metal plate (material: mild steel, $1.8 \mathrm{~m} \mathrm{X} 1.2 \mathrm{~m}$, thickness $3 \mathrm{~mm}$ ) and is referred as focus plate. The focus plate was mounted at 13 meter from the heliostats. The arrangements were done such that the receiver received all the reflected rays from the concentrators. The size of image area is calculated and is found to be $1.25 \mathrm{~m} 2$. Here 16 thermocouples are fixed in a grid of 4X4; with distance between two thermocouples is $300 \mathrm{~mm}$, the thermocouple grid thus cover an area of $0.9 \mathrm{~m} \mathrm{X} 0.9 \mathrm{~m}$. Each thermocouple indicates the average temperature of grid area of $0.3 \mathrm{~m}$ $X 0.3 \mathrm{~m} .16$ number of small bore of diameter $3 \mathrm{~mm}$ and $2 \mathrm{~mm}$ deep were made on the back side of the plate. The thermocouple was fixed in the bore by brazing. A layer of ceramic wool insulation of thickness $25 \mathrm{~mm}$ (standard size) is provided over the thermocouples to minimize the heat losses. Two insulation sheets of size 2 feet X 4 feet are used to cover the thermocouples from the back side to prevent heat losses.

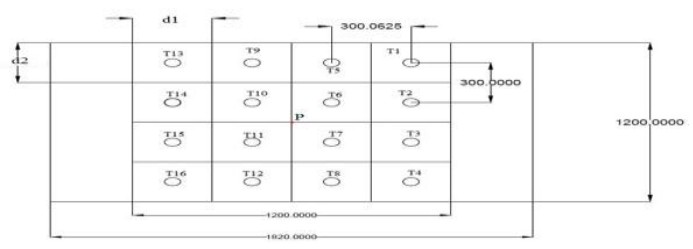

Fig.3. Schematic diagram of the receiver plate with the thermocouple position

\subsection{Heliostat}

This heliostat system is designed by Dr. Ravindra Patwardhan and has applied for US Patent [23]. Generally a conventional heliostat is mounted on a pedestal and is pivotally rotatable about altitudinal and azimuthal axes. Each axis is equipped with a motorized limb that can pivotally rotate the mirror of the heliostat to adjust its position. Thus in conventional system for a single heliostat 2 motors are required and the size of the motor changes with the size of the heliostat. In the presented system, a number of heliostats are mechanically oriented and linked on a rotatable shaft. The advantage of this linked mechanism on a rotatable shaft is that all the heliostats on the can be controlled by a single DC motor and actuator arm. This helps in 
significantly cutting the cost of motors used in conventional system. Following are the figures of heliostat:

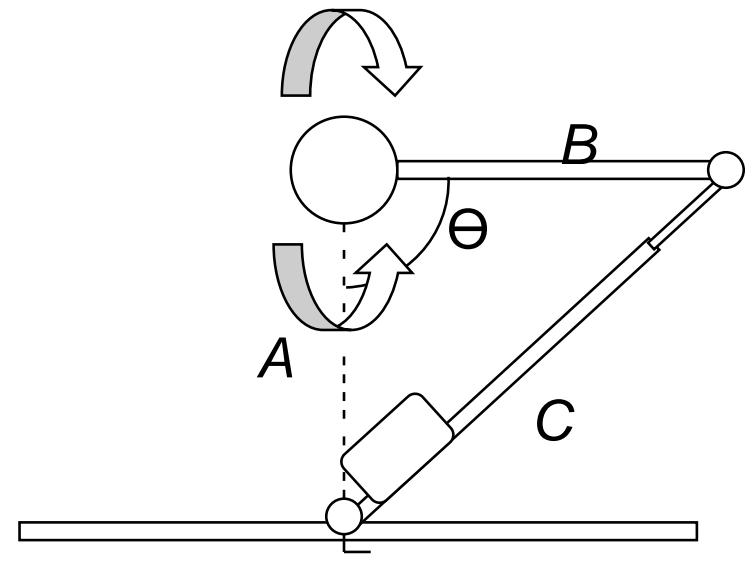

Fig.4.Actutator mechanism to control the elevation motion of the heliostat

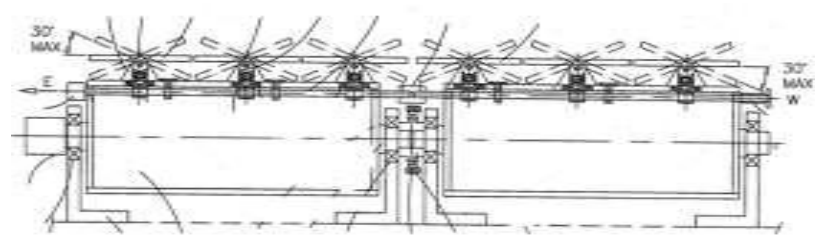

Fig.5.schematic diagram of mechanically linked Heliostat

All the mirrors are mounted on a single shaft, the shaft is given motion using DC motor, this DC motors tracks the azimuthal motion of the sun while the actuator mechanism helps in tracking the elevation motion of the sun, the description has been explained in the patent file by Dr. Ravindra Patwardhan.

\subsection{Testing Procedure}

1) The focus plate of size $1.8 \mathrm{~m} \mathrm{X} 1.2 \mathrm{~m}$, as only single array of heliostat was used and due to space constraint, the receiver plate was kept at a distance of $13 \mathrm{~m}$ from the heliostats.

2) Thermocouples are fixed on the focus plate at a distance of $300 \mathrm{~mm}$ apart, 16 thermocouples are used covering an area of $1.2 \mathrm{~m}^{2}$.

3) The heliostat unit is started and the automatic tracking begins.

4) Thermocouple readings, wind speed and solar radiation are measured every 20 mins.

5) The program was such that the tracking would begin when the sun elevation angle would reach 450 in the morning and would stop when sun angle would reach 450 in the afternoon. The time for the sun angle was from $9300 \mathrm{hrs}$ to $1540 \mathrm{hrs}$, hence the reading was taking between $1000 \mathrm{hrs}$ to $1530 \mathrm{hrs}$.

\section{Numerical Work}

In central receiver technology radiation reflected from the heliostat field forms a variation of flux density distribution on the receiver surface. This flux distribution shown by using soltrace software for the same parameter which is used in experimental work. For comparison of experimental work and Numerical work, here 3rd and 4th june is considered.

Form the soltrace software data has been taken for different time at the day of 3rd june. This data is import in the MATLAB software and plot a contour with help of Matlab program. In the same way this procedure is repeat for the 4th june. Following figure shows the numerical work of 3rd june.

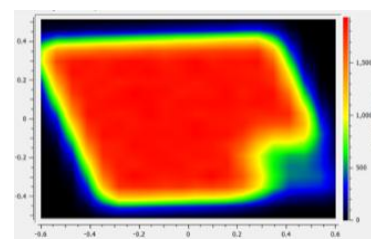

(a)

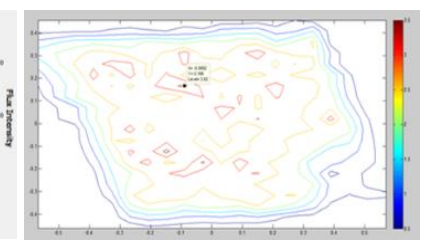

(b)
Fig. 6. (a)Flux Image on the receiver of 4 heliostats (1st Row) (b) Flux contour plotted in MATLAB software

(Day-3june and Hour-11am)

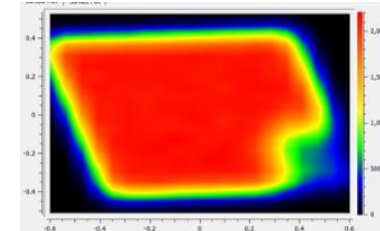

(a)

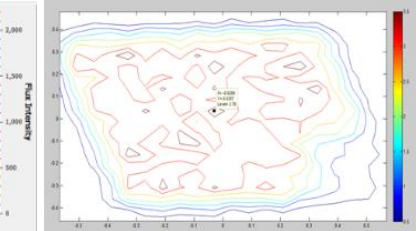

(b)
Fig. 7. (a)Flux Image on the receiver of 4 heliostats (1st Row) (b) Flux contour plotted in MATLAB software (Day-3june and Hour-11.20am)

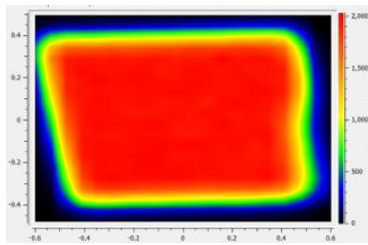

(a)

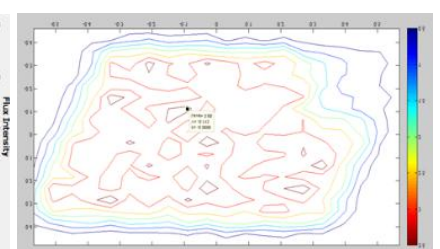

(b)
Fig. 8. (a)Flux Image on the receiver of 4 heliostats (1st Row) (b) Flux contour plotted in MATLAB software (Day-3june and Hour-12pm).

The above analysis shows the flux distribution on the central receiver. Also it shows the fluctuation in flux on the receiver plate, it also show the peak and average flux. This analysis result compare with the experimental result. From this comparison it is clear that where the peak flux is generated and how much 
amount of flux is reduce for even flux distribution. In the same way analysis and comparison of experiment work and numerical work is done for the 4th June.

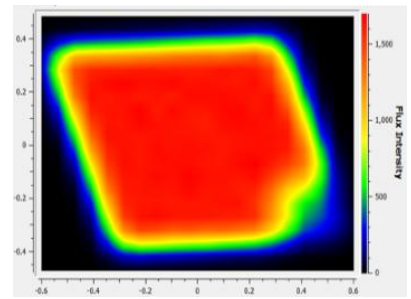

(a)

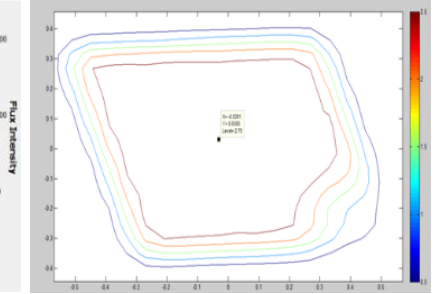

(b)
Fig 9. (a)Flux Image on the receiver of 4 heliostats (1st Row) (b) Flux contour plotted in MATLAB software (Day-4june and Hour-11am)

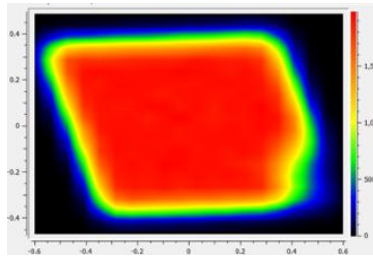

(a)

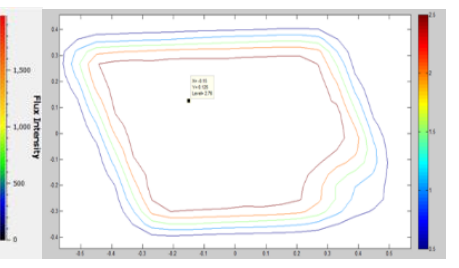

(b)
Fig. 10. (a)Flux Image on the receiver of 4 heliostats (1st Row) (b) Flux contour plotted in MATLAB software (Day-4june and Hour-11.20am).

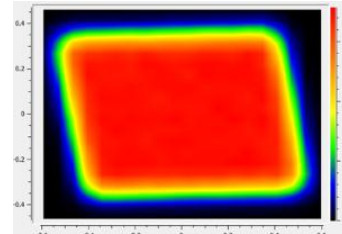

(a)

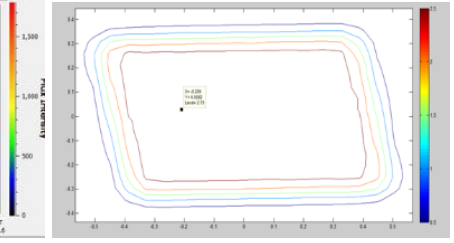

(b)
Fig. 11. (a)Flux Image on the receiver of 4 heliostats (1st Row) (b) Flux contour plotted in MATLAB software (Day-4june and Hour-12pm).

Form the experimental work flux is calculate by considering the heat loss from both side of receiver plate, but cause of insulation on back side only front side heat losses are consider. Receiver having thickness of $3 \mathrm{~mm}$ that cause conduction loss of receiver plate is negligible, as compared to the radiation and convection loss from the front side. Here only three heat losses are consider convective, conductive loss from the front side of receiver plate and conductive loss through the insulation. Thus equation (1) can be written as,

Absorbed energy $=$ Energy loss by conduction + Energy loss by convection+ Energy loss by Re-radiation $\mathrm{Q}_{\mathrm{c}}(\mathrm{r})=\left[\mathrm{h}\left(\mathrm{T}_{\mathrm{r}}-\mathrm{T}_{\mathrm{amb}}\right)+\xi \sigma\left(T_{r}^{4}-T_{a m b}^{4}\right)+\frac{K_{i}}{L}\left(T_{r}-T_{a m b}\right] / \alpha\right.$
Where,

$\Phi_{c}(r)$ solar flux at a distance ' $r$ ' from the center of the focus, $\mathrm{W} / \mathrm{m}^{2}$

$\mathrm{H}$ is the convective heat transfer coefficient of the focus plate, $\mathrm{W} / \mathrm{m}^{2} \mathrm{~K}$

$\mathrm{T}_{\mathrm{r}}$ is the temperature of the strip at radius ' $r$ ' from the center of the focus, $\mathrm{K}$

$\mathrm{T}_{\mathrm{amb}}$ is the ambient temperature, $\mathrm{K}$.

$\sigma$ is the Stefan-Boltzmann constant, $\mathrm{W} / \mathrm{m}^{2} \mathrm{~K}^{4}$.

$\epsilon$ is the emissivity of the plate.

$\alpha$ is the absorptance of the plate for solar radiation.

$\mathrm{K}_{\mathrm{i}}$ is the thermal conductivity of the insulation, $\mathrm{W} / \mathrm{m}-\mathrm{K}$.

\section{Result and Discussion}

In the experimental work 16 thermocouple show the temperature of receiver plate, based on the temperature records of the focus plate, flux is calculated by using the formula No. (2), the following values have been used for the calculations:

- Thermal conductivity of insulation $=0.12 \mathrm{~W} / \mathrm{m}-\mathrm{K}$

- Thickness of insulation $=0.025 \mathrm{~m}$

- Absorptivity of focus plate in solar spectrum = 0.8951

Table 1 Calculation of flux based on the experimental temperature value (4th June, Hour: 12.40 ).

\begin{tabular}{|c|c|c|c|c|c|}
\hline \multicolumn{2}{|c|}{ Element } & \multicolumn{4}{|c|}{ Flux $\left(\mathrm{W} / \mathrm{m}^{2}\right)$} \\
\hline$\dot{z}$ & 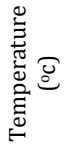 & 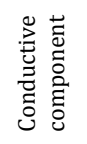 & 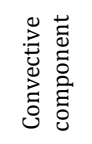 & 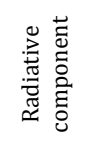 & 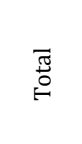 \\
\hline $\mathrm{T} 1$ & 60 & 218.50 & 157.58 & 110.40 & 543.49 \\
\hline $\mathrm{T} 2$ & 90 & 503.50 & 370.17 & 254.40 & $\begin{array}{c}1260.2 \\
7\end{array}$ \\
\hline $\mathrm{T} 3$ & 80 & 408.50 & 293.15 & 206.40 & $\begin{array}{c}1014.4 \\
6\end{array}$ \\
\hline $\mathrm{T} 4$ & 54 & 161.50 & 121.39 & 81.60 & 407.20 \\
\hline $\mathrm{T} 5$ & 76 & 370.50 & 264.12 & 187.20 & 918.13 \\
\hline T6 & 130 & 883.50 & 748.36 & 446.40 & $\begin{array}{c}2321.8 \\
2\end{array}$ \\
\hline $\mathrm{T} 7$ & 120 & 788.50 & 642.54 & 398.40 & $\begin{array}{c}2043.8 \\
3\end{array}$ \\
\hline $\mathrm{T} 8$ & 57 & 190.00 & 139.24 & 96.00 & 475.07 \\
\hline T9 & 88 & 484.50 & 354.24 & 244.80 & $\begin{array}{c}1210.5 \\
3 \\
\end{array}$ \\
\hline $\mathrm{T} 10$ & 131 & 893.00 & 759.39 & 451.20 & $\begin{array}{c}2350.1 \\
1\end{array}$ \\
\hline T11 & 120 & 788.50 & 642.54 & 398.40 & $\begin{array}{c}2043.8 \\
3\end{array}$ \\
\hline T12 & 54 & 161.50 & 121.39 & 81.60 & 407.20 \\
\hline $\mathrm{T} 13$ & 68 & 294.50 & 208.97 & 148.80 & 728.72 \\
\hline $\mathrm{T} 14$ & 94 & 541.50 & 402.81 & 273.60 & $\begin{array}{c}1360.6 \\
5\end{array}$ \\
\hline $\mathrm{T} 15$ & 92 & 522.50 & 386.36 & 264.00 & $\begin{array}{c}1310.3 \\
1 \\
\end{array}$ \\
\hline T16 & 50 & 123.50 & 98.34 & 62.40 & 317.5 \\
\hline
\end{tabular}


Table 2 Comparison of experimental work and Numerical work

\begin{tabular}{|c|c|c|c|c|c|c|}
\hline Sr. No. & & & \multicolumn{2}{|c|}{$\begin{array}{l}\text { Experimental } \\
\text { valuve }\end{array}$} & \multicolumn{2}{|c|}{ Numerical valve } \\
\hline 1 & $\overrightarrow{\widetilde{\sigma}}$ & 亏ે & 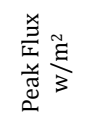 & 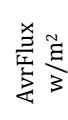 & 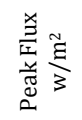 & $\underset{\frac{x}{3}}{\stackrel{x}{3}}$ \\
\hline 2 & $\begin{array}{c}\text { 3rd } \\
\text { june }\end{array}$ & $11 \mathrm{am}$ & $\begin{array}{c}2232.5 \\
5\end{array}$ & $\begin{array}{c}975.7 \\
6\end{array}$ & $\begin{array}{c}2194.1 \\
8\end{array}$ & $\begin{array}{c}899.99 \\
4\end{array}$ \\
\hline 3 & $\begin{array}{c}\text { 3rd } \\
\text { june }\end{array}$ & $\begin{array}{c}11.20 \mathrm{a} \\
\mathrm{m}\end{array}$ & $\begin{array}{c}2768.3 \\
4\end{array}$ & $\begin{array}{c}1194 . \\
63\end{array}$ & $\begin{array}{c}2197.3 \\
9\end{array}$ & 1136.9 \\
\hline 4 & $\begin{array}{c}\text { 3rd } \\
\text { june }\end{array}$ & $12 \mathrm{pm}$ & $\begin{array}{c}2399.7 \\
2\end{array}$ & $\begin{array}{c}1193 . \\
62\end{array}$ & $\begin{array}{c}2335.0 \\
3\end{array}$ & $\begin{array}{c}1327.1 \\
3\end{array}$ \\
\hline 5 & $\begin{array}{c}\text { 3rd } \\
\text { june }\end{array}$ & $13 \mathrm{pm}$ & $\begin{array}{c}2626.0 \\
4\end{array}$ & $\begin{array}{c}1258 . \\
92\end{array}$ & $\begin{array}{c}2315.5 \\
1\end{array}$ & $\begin{array}{c}1386.6 \\
7\end{array}$ \\
\hline 6 & $\begin{array}{l}\text { 4th } \\
\text { june }\end{array}$ & $11 \mathrm{am}$ & $\begin{array}{c}2206.9 \\
1\end{array}$ & $\begin{array}{c}1097 . \\
01\end{array}$ & $\begin{array}{c}1926.4 \\
4\end{array}$ & 905.75 \\
\hline 7 & $\begin{array}{l}\text { 4th } \\
\text { june }\end{array}$ & $\begin{array}{c}11.20 \mathrm{a} \\
\mathrm{m}\end{array}$ & $\begin{array}{c}2338.7 \\
2\end{array}$ & $\begin{array}{c}1123 . \\
30\end{array}$ & $\begin{array}{c}2249.6 \\
1\end{array}$ & $\begin{array}{c}1073.2 \\
7\end{array}$ \\
\hline 8 & $\begin{array}{l}\text { th } \\
\text { june }\end{array}$ & $12 \mathrm{pm}$ & $\begin{array}{c}2092.4 \\
5\end{array}$ & $\begin{array}{c}1109 . \\
43\end{array}$ & $\begin{array}{c}2040.6 \\
3\end{array}$ & $\begin{array}{c}1043.2 \\
5\end{array}$ \\
\hline 9 & $\begin{array}{l}\text { 4th } \\
\text { june }\end{array}$ & $13 \mathrm{pm}$ & $\begin{array}{c}2208.2 \\
3\end{array}$ & $\begin{array}{c}917.5 \\
1\end{array}$ & $\begin{array}{c}2085.3 \\
6\end{array}$ & $\begin{array}{c}1147.6 \\
9\end{array}$ \\
\hline
\end{tabular}

The above table shows that Numerical flux value slightly less than the experimental flux valve.

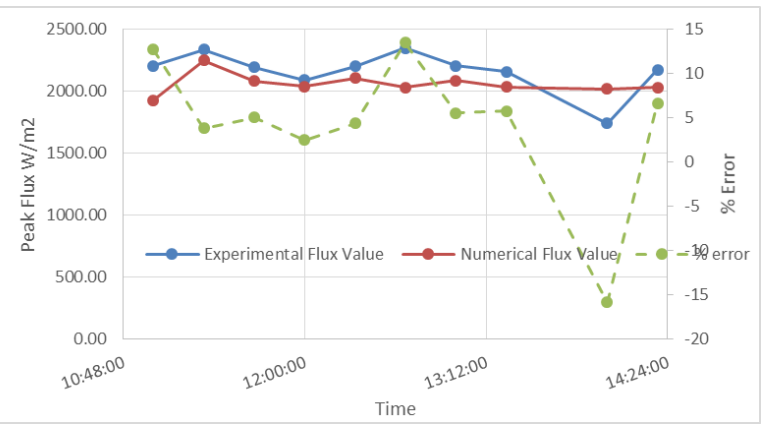

Fig. 12. Comparison of Experimental peak Flux and Numerical peak flux ( $4^{\text {th }}$ June)

From the above figure it is clear that numerical and experimental peak flux valve are near about same and it also shows that the highest error valve is $15 \%$. It means experimental result is valid by cross-checking with numerical result .Also by using numerical method peak flux value of 100 heliostat field can be calculated. This 100 heliostat field consist of five row and each row having 20 heliostat.

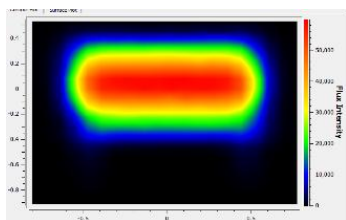

(a)

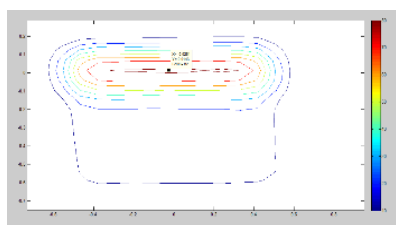

(b)
Fig. 13. (a)Flux Image on the receiver of 100 heliostats (All five Rows) (b) Flux contour plotted in MATLAB software (Day-3june and Hour-12.30pm)

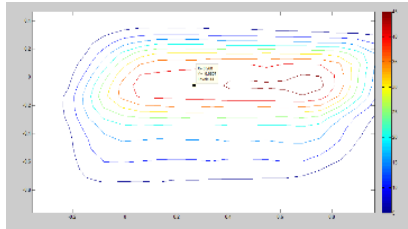

(a)

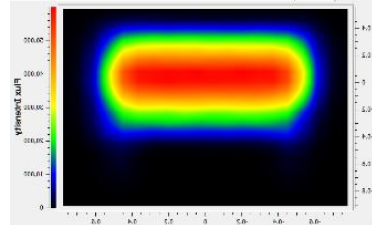

(b)
Fig. 14. (a)Flux Image on the receiver of 100 heliostats (All five Rows) (b) Flux contour plotted in MATLAB software (Day-4june and Hour-12.30pm).

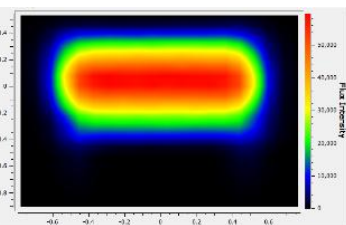

(a)

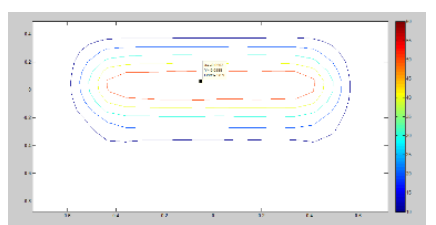

(b)
Fig. 15. (a)Flux Image on the receiver of 100 heliostats (All five Rows) (b) Flux contour plotted in MATLAB software (Day-21june and Hour-12.30pm).

\section{Conclusions}

The work in this paper presents comparison of experimental and Numerical work of flux distribution on the receiver plate. The analysis has shown that flux distribution receiver surface has huge impact on the receiver life and efficiency of central receiver technology. Comparison of Experimental peak flux valve and numerical peak flux value shows that it has very less difference. The Soltrace software is good for comparison and validation, because it has only $15 \%$ error on the experimental flux value. From this result also prediction of maximum allowable flux density is very easy. From the numerical analysis with help of Soltrace software and experimental dada whole field of 100 heliostat can be modified and modelled.

\section{Acknowledgement}

The authors would like to thank Dr. Ravindra Patwardhan sir and Mr. Akole sir for providing the research facility.

\section{References}

Igel, E. A., and Hughes, R. L., (1979) Optical Analysis of Solar Facility Heliostats, Sol. Energy, 22, pp. 283-295.

C. A. Kinjavdekar, V. p. Muley, S. B. Kedare and J. K. Nayak,(2010) A test procedure for determining optical characteristics of a dish concentrator and its implementation on a Scheffler dish, SESI Journal, Vol. No 20.

V. Rakesh Sharma, S. J. Bhosale, S. B. Kedare, J. K. Nayak, A simple method to determine optical quality of paraboloid concentrate solar thermal collector, Energy systems Engineering 
Glen Johnston (1998), Focal region measurements of the 20 m2 Tiled dish at the Australian national university, Solar energy Vol. 63 No. 2. Pp. 117-124

Lorin L. Vant-Hull (2002), The Role of Allowable Flux Density in the Design and Operation of Molten-Salt Solar Central Receivers, Solar Energy Engineering.

Alberto Sanchez-Gonzalez, Domingo Santana (2014), Solar flux distribution on central receivers: A projection method from analytic function', Renewable energy 74, 576 - 587.

Clifford K. Ho, Siri S. Khalsa (2011), A flux mapping method for central receiver systems, Proceedings of the ASME.

F. Gohring, O. Bender (2011), Flux density measurement on open volumetric receiver, Proceedings of SolarPACES.

J. Ballestrin, R. Monterreal (2014), Hybrid heat flux measurement system for solar central receiver evaluation, Energy 29, 915 - 924.

Zhirong Liao a, Xin Li , Chao Xu , Chun Chang , Zhifeng Wang(2013), Allowable flux density on a solar central receiver, Renewable energy 62,747-753.

Grobler, A. and Gauché, P. (2014), A review of aiming strategies for central receivers. Proceedings of the 2nd SASEC conference, Port Elizabeth, South Africa

Salomé, A., Chhel, F., Flamant, G., Ferrière, A. and Thiery, F. (2013) Control of the flux distribution on a solar tower receiver using an optimized aiming point strategy: Application to THEMIS solar tower. Solar Energy, vol. 94, pp. 352-366

Belhomme, B., Pitz-Paal, R. and Schwarzbözl, P.(2013) Optimization of heliostat aim point selection for central receiver systems based on the ant colony optimization metaheuristic. Journal of Solar Energy Engineering, vol. 136.
Augsburger, G. and Favrat, D. (2013) Modelling of the receiver transient flux distribution due to cloud passages on a solar tower thermal power plant. Solar Energy, vol. 87 pp. $42-52$.

Kelly, B.D.(2010) Advanced thermal storage for central receivers with supercritical coolants. Tech. Rep., Abengoa Solar Inc.

García-Martín, F., Berenguel, M., Valverde, A. and Camacho, E.(1999) Heuristic knowledge-based heliostat field control for the optimization of the temperature distribution in a volumetric receiver. Solar Energy, vol. 66, no. 5, pp. 355369.

Dorigo, M. and Gambardella, L.(1997) Ant colony system: a cooperative learning approach to the travelling salesman problem. Evolutionary Computation, IEEE, vol. 1, no. 1, pp 53-66.

Varun, Siddhartha.(2010) Thermal performance optimization of a flat plate solar air heater using genetic algorithm. Appl Energy ; 87:1793-9.234-243.

Kalogirou SA.(2004) Optimization of solar systems using artificial neural-networks and genetic algorithms. Appl Energy; 77:383-405.

Saeb M. Besarati, D. Yogi Goswami, Elias K. Stefanakos,(2014) Optimal heliostat aiming strategy for uniform distribution of heat flux on the receiver of a solar power tower plant. Energy Conversion and Management 84 .

Zhirong Liao a, b, Xin Li , Chao Xu , Chun Chang, Zhifeng Wang (2013) Allowable flux density on a solar central receiver, Renewable Energy .

Francisco J. Collado(2010) "One-point fitting of the flux density produced by a heliostat", Solar Energy Engineering

Patwardhan et al.(2011) 'Solar central receiver system employing common positioning mechanism for heliostats', United States Patent Application. 